\title{
Analysis of haptic, visual, and verbal presentation mode effects in children's paired associate learning
}

\author{
DANIEL W. KEE and BERYL R. DAVIS \\ University of Southern California, Los Angeles, California 90007
}

\begin{abstract}
The experiment was conducted to assess the relative effectiveness of three different presentation modes on children's paired associate learning. Thirty-six second-grade children served as subjects. A study-test paired associate recognition procedure was used. The study trial consisted of the presentation of a 20-pair list of common objects in one of three different presentation conditions: haptic object vs. visual object vs. aural label. On the test trial, the children were presented with both original and repaired items in the same mode as study for an old vs. new recognition response. The results indicated that visual-object presentation was superior to both haptic-object and aural-label presentations, which did not differ from each other.
\end{abstract}

An important issue in children's paired associate learning is the identification of effective modes for presenting to-be-remembered (TBR) stimuli (e.g., Pressley, 1977; Reese, 1977; Rohwer, 1973). A frequent comparison in the literature has been between the verbal presentation of object labels vs. the visual presentation of object drawings. In such comparisons, the usual finding is that visual presentation is associated with a higher level of paired associate performance than verbal presentation (e.g., Rohwer, Kee, \& Guy, 1975). Research also suggests that the haptic-object mode of presentation can influence children's paired associate performance. For example, Irwin (1971) demonstrated that paired associate performance is enhanced when children are allowed to handle and look at TBR toy objects relative to merely looking at the objects side by side. A complementary finding has been reported by Wolff and Levin (e.g., Wolff \& Levin, 1972; Wolff, Levin, \& Longobardi, 1972). In the Wolff and Levin research, children given an opportunity to act out an interaction between the TBR toy objects under interactive imagery instructions are typically associated with a higher level of paired associate performance than children who are only allowed to look at the TBR objects side by side under the imagery instructional prompt.

The studies concerning the influence of haptic-object

This research was supported in part by a grant from the Research and Publication Fund, University of Southern California. The authors express their appreciation to the children, teachers, and administrators of the El Rodeo, Hawthorne, and Horace Mann Schools of the Beverly Hills Unified School District for their assistance in the completion of the research. Reprint requests should be sent to Daniel W. Kee, Department of Psychology, University of Southern California, University Park, Los Angeles, California 90007. presentation on children's paired associate learning clearly indicate that this type of presentation can augment the performance associated with visual-object presentation. However, the effectiveness of the hapticobject mode relative to the verbal or pictorial modes is unknown. Thus, the present study was designed to provide an evaluation of the relative effectiveness of the three different presentation modes in children's paired associate learning.

\section{METHOD}

\section{Subjects and Design}

Thirty-six second-grade children with a mean age of 7.85 years $(S D=4.31$ months, range $=7.25-8.83$ ) from the high socioeconomic status community of Beverly Hills, California, participated as subjects in the experiment. The children were randomly assigned to one of the three presentation conditions in the study: haptic object vs. visual object vs. aural label.

\section{Materials and Procedure}

A 20-pair list of common toy objects (e.g., balloon, car, shovel, etc.) was assembled for use in the study. All of the toys were small enough (between 7.50 and $10.50 \mathrm{~cm}$ ) for the children to hold comfortably in one hand, yet large enough for them to identify by touch alone. Pilot testing with the objects indicated that they were all highly identifiable by sight, touch, and name with children as young as preschool. The item labels used in the study were selected by pilot testing, utilizing those labels most commonly given by the children for the objects. For the test trial of the study, the basic 20-pair list was altered so that half of the pairs were old (i.e., pairs were identical with the study trial), while half of the pairs were new (i.e., re-paired). Two different test lists were used in order to counterbalance old and new pairs such that old pairs in one list would serve as the new (i.e., re-paired) items in the other list.

The subjects were tested individually in a quiet room at the participating school by a female experimenter. The subjects were seated at a table across from the experimenter. The subjects were told that they were going to play a memory game in which they would handle, see, or be told the names of toy objects. 
On the study trial, the subjects were presented with the TBR toy objects at a $10-\mathrm{sec} /$ pair rate. In the aural-label presentation condition, the experimenter read the subjects the names of the 20 pairs of objects. Each pair was named three times for the children in order to equate the length of stimulus presentation with that in the visual-object and haptic-object modes. The visual-object condition consisted of the experimenter visually presenting one object of the pair immediately followed by the second, then holding the TBR pair members side by side in front of the child for the duration of the presentation interval. Finally, for the haptic-object condition, the subjects blindly handled each of the objects in the pair. The objects were handed to the children in the same order in which they were named in the aural-label condition and presented visually in the visualobject condition. A cardboard box was used in which two holes had been cut out through which the subjects could insert their hands. A cloth curtain covered the opening to prevent the subjects from seeing the toys. The back of the box was open, thereby allowing the experimenter to place the toys in the subjects' hands. Each of the presentation conditions in the study was pure. That is, the subjects were presented with TBR pairs in only one mode. For example, at no time did subjects in the haptic-object presentation condition see the objects or hear their names.

Approximately $60 \mathrm{sec}$ after the completion of the study trial, a single-subject paced recognition test trial was administered. This test consisted of the presentation of the old and new pairs in a random order for an old-new recognition response. Presentation of pairs on the test trial corresponded with the presentation mode used at study.

\section{RESULTS AND DISCUSSION}

Two indices of recognition performance were examined: (1) a corrected recognition score, the difference between hits (subject responds "old" to an old pair) and false alarms (subject responds "old" to a new pair), and (2) the $\mathrm{d}^{\prime}$ index of signal detection theory (cf. Banks, 1970). Analysis indicated that identical patterns of recognition performance were reflected by each variable. The Pearson coefficient of correlation between the two measures was near unity $(+.96)$. Since the corrected recognition score provides a more meaningful measure of performance than $d^{\prime}$ for comparison with previous studies concerned with presentation-mode effects on children's paired associate learning, only the analysis conducted on the corrected recognition scores is treated in the present results. The Type I error rate for all tests was set at .05 .

Table 1 presents the mean corrected recognition scores for the experimental conditions. The analysis of variance performed indicated a significant main effect for presentation condition $[\mathrm{F}(2,33)=6.41]$. Pairwise comparisons were made by the Scheffé method and revealed that the visual-object condition was associated with a higher level of performance than both the haptic-object and aural-label presentation conditions, which did not differ from each other.

The finding that visual-object presentation is superior to aural-label presentation is consistent with previous research. One interpretation of this outcome can be advanced in terms of Paivio's (1971) suggestion that
Table 1

Mean Corrected Recognition Scores as a Function of Presentation Condition

\begin{tabular}{ccc}
\hline \multicolumn{3}{c}{ Presentation Condition } \\
\hline Haptic Object & Visual Object & Aural Label \\
\hline 2.75 & 6.08 & 2.91 \\
\hline
\end{tabular}

Note-MSe (33) $=6.61$.

both verbal and imagery representational codes can underlie the encoding of concrete stimuli. Adults frequently use both forms of representation for efficient encoding (i.e., dual coding), whereas in young children, the representational code used can be influenced by the method of stimulus presentation. For example, the verbal presentation of TBR pairs induces primarily verbal coding, whereas the visual-object or pictorial presentation of TBR pairs elicits primarily imagery encoding (cf. Kee, 1976). Thus, the superiority of visual-object vs. aural-label presentations can be interpreted to reflect the greater hospitality of the imagery code relative to the verbal code for the formation of relationships between concrete stimuli (cf. Paivio, 1971).

In addition to the verbal and imagery forms of representation, a third form is suggested in the literature (e.g., Bruner, 1967; Piaget, 1952). Representation within this code consists of the actions (e.g., motor) that the child engages in during the manipulation of objects. Bruner has labeled this code the enactive form of representation. If specific encoding within this representational form is elicited by haptic-object presentation, the pattern of presentation-mode effects observed in the study can be interpreted to suggest that the imagery code is superior to both the verbal and enactive for the formation of pairwise relationships between concrete stimuli.

The foregoing interpretation requires a subscription to the notion that each of the presentation modes elicits specific encoding within a different representational form. Alternate interpretations of the pattern of results can be entertained that do not maintain such a subscription. For example, the relative effectiveness of the three modes of presentation may reflect the different number of representational codes elicited (i.e., a multiple-encoding hypothesis). Alternately, the presentation modes may differ in their effectiveness to successfully establish relationships between pair members within a single semantic code (e.g., Rohwer, 1973). A selection between these different explanations, however, is beyond the purview of the present study, which was designed to provide the first direct assessment of the relative effectiveness of the three different presentation modes in children's paired associate learning. In this regard, the results of the study are clear: The visual-object presentation condition was associated with a higher level of performance than both 
the haptic-object and aural-label presentation conditions, which did not differ from each other.

\section{REFERENCES}

Banks, W. P. Signal detection theory and human memory. Psychological Bulletin, 1970, 74, 81-99.

Bruner. J. S. On cognitive growth I. In J. S. Bruner, R. R. Olver, \& P. M. Greenfield (Eds.), Studies in cognitive growth. New York: Wiley, 1967.

KEE, D. W. Storage and retrieval of noun-pairs in chidren's recognition memory: Analysis of presentation mode and elaboration effects. Journal of Experimental Psychology: Human Learning and Memory, 1976, 2, 623-632.

IRWIN, M. H. Developmental study of elaboration modality effects in children's paired-associated memory. Unpublished doctoral dissertation, University of California, Berkeley, 1971.

Paivio, A. Imagery and verbal processes. New York: Holt, Rinehart, and Winston, 1971.

PIAGET, J. The origins of intelligence in children. New York: Norton, 1952.
Pressley, M. Imagery and children's learning: Putting the picture into developmental prospective. Review of Educational Research, 1977, 47, 585-622.

REESE, H. W. Imagery and associative memory. In R. V. Kail, Jr., \& J. W. Hagen (Eds.), Perspectives on the development of memory and cognition. Hillsdale, N.J.: Erlbaum, 1977.

RoHWER, W. D., JR. Elaboration and learning in childhood and adolescence. In H. W. Reese (Ed.), Advances in child development and behavior (Vol. 8). New York: Academic Press, 1973.

RohWER, W. D., JR., KeE, D. W., \& GUY, K. C. Developmental changes in the effects of presentation media on noun-pair learning. Journal of Experimental Child Psychology, 1975, 19, 137-152.

WolfF, P., \& Levin, J. R. The role of overt activity in children's imagery production. Child Development, 1972, 43, 537-547.

Wolff, P., LeVin, J. R., \& Longobardi, E. T. Motoric mediation in children's paired-associate learning: Effects of visual and tactual contact. Journal of Experimental Child Psychology, 1972, 5, 394-406.

(Received for publication January 16, 1979.) 